\title{
ANALISIS PERHITUNGAN DAN PELAPORAN PAJAK PENGHASILAN PASAL 23 PADA PT. HASJRAT MULTIFINANCE, MANADO
}

\author{
Rachel Romilda Rampengan \\ David Paul Elia Saerang \\ Inggriani Elim
}

Fakultas Ekonomi dan Bisnis, Jurusan Akuntansi

Universitas Sam Ratulangi Manado

e-mail: artchel280909@yahoo.com

\begin{abstract}
ABSTRAK
Pajak Penghasilan Pasal 23 ( $\mathrm{PPh}$ Pasal 23), mengatur pemotongan pajak yang dikenakan atas penghasilan Wajib Pajak di dalam negeri atau Bentuk Usaha Tetap (BUT) yang berasal dari modal, penyerahan jasa, atau penyelenggaraan kegiatan selain yang telah dipotong Pajak Penghasilan Pasal 21. Penelitian ini bertujuan untuk mengetahui perhitungan serta perlakuan akuntansi dari Pajak Penghasilan pasal 23 dan mengetahui pelaporan pajak yang telah dilaksanakan oleh PT. Hasjrat Multifinance, Manado apakah telah sesuai dengan ketentuan yang berlaku. Objek penelitian ini diambil pada PT. Hasjrat Multifinance, Manado dengan menggunakan metode analisis deskriptif kualitatif. Dari hasil penelitian dapat disimpulkan bahwa PT. Hasjrat Multifinance, Manado telah melakukan perhitungan dan pelaporan PPh Pasal 23 secara benar yaitu sesuai dengan ketentuan. Untuk penyetoran paling lambat tanggal 10 bulan berikutnya sedangkan untuk pelaporan paling lambat 20 hari setelah masa pajak berakhir.
\end{abstract}

Kata kunci : pph pasal 23, perhitungan dan pelaporan pph pasal 23

\begin{abstract}
Income Tax Article 23 ( article 23 ), set cutting taxes imposed on income taxpayer in the country or Permanent Establishment (PE ) derived from the capital, the delivery of services, or implementation of activities other than those of Article 21 Income Tax withheld.This study aims to determine the calculation as well as the accounting treatment of income tax article 23 and to know the tax reporting has been carried out by PT . Hasjrat Multifinance, Manado whether in accordance with applicable regulations . Object of this study was taken at. Hasjrat Multifinance, Manado using qualitative descriptive analysis method. From the results of this study concluded that PT . Hasjrat Multifinance, Manado has done the calculation and reporting of article 23 are right that is in accordance with the provisions. To deposit no later than the 10th of the next month while reporting not later than 20 days after the tax period ends .
\end{abstract}

Keywords : income tax article 23 , income tax calculation and reporting article 23 


\section{PENDAHULUAN}

\section{Latar Belakang}

Dengan perkembangan ekonomi tersebut menyebabkan munculnya kebutuhan-kebutuhan ekonomi yang harus dipenuhi khususnya negara Indonesia. Dengan adanya pengaruh dari negara-negara lain diluar Indonesia, pemerintah perlu memperbaharui sistem-sistem yang sudah dianggap usang agar dapat sesuai dengan zaman modern dalam hal mencakup perpajakan. Pengembangan dan perluasan usaha tersebut dalam upaya untuk bertahan dan mampu bersaing dengan perusahaan-perusahaan yang baru atau perusahaan yang sudah berkembang serta memenuhi kebutuhan para konsumen atau pengguna jasa atau produk perusahaan itu sendiri. Banyak cara yang ditempuh oleh perusahaan guna memenuhi kebutuhan pasar. Salah satunya dengan upaya dalam perluasan dan pengembangan usaha.

Pajak merupakan hal yang wajib untuk dibayarkan demi terciptanya keseimbangan kondisi ekonomis dalam negara. Pembiayaan yang dilakukan dalam negeri bergantung pada seberapa banyak dan tekunnya suatu Wajib Pajak dalam melakukan pembayaran pajak. Atau dapat dikatakan bahwa pemungutan pajak merupakan perwujudan dari pengabdian kewajiban dan peran serta wajib pajak yang secara langsung dan bersama-sama melaksanakan kewajiban perpajakan yang diperlukan untuk pembiayaan negara dan pembangunan nasional. Jika dilihat dari penerimaan negara, kondisi keuangan negara tidak lagi semata-mata dari penerimaan negara berupa minyak dan gas bumi, tetapi lebih berupaya untuk menjadikan pajak sebagai primadona penerimaan negara.

Ketentuan dalam pasal $23 \mathrm{UU}$ PPh mengatur pemotongan pajak atas penghasilan yang diterima atau diperoleh wajib pajak dalam negeri dan Bentuk Usaha Tetap yang berasal dari modal, penyerahan jasa, atau penyelenggaraan kegiatan selain yang telah dipotong Pajak Penghasilan Pasal 21, yang dibayarkan, disediakan untuk dibayarkan, atau telah jatuh tempo pembayarannya oleh badan pemerintah, subjek pajak badan dalam negeri, penyelenggara kegiatan, bentuk usaha tetap, atau perwakilan perusahaan luar negeri lainnya. Peneliti tertarik untuk membahas pengenaan pajak dipihak badan usaha dikaitakan dengan Pajak Penghasilan pasal 23 sehingga peneliti mengangkat judul ANALISIS PERHITUNGAN DAN PELAPORAN PAJAK PENGHASILAN PASAL 23 PADA PT. HASJRAT MULTIFINANCE, MANADO.

\section{Tujuan Penelitian}

Tujuan yang ingin dicapai dari penelitian ini, yaitu:

Mengetahui perhitungan serta perlakuan akuntansi dari Pajak Penghasilan pasal 23 dan mengetahui pelaporan pajak yang telah dilaksanakan oleh PT. Hasjrat Multifinance, Manado apakah telah sesuai dengan ketentuan yang berlaku.

\section{TINJAUAN PUSTAKA}

\section{Akuntansi Perpajakan}

Muljono (2009:27) menyatakan bahwa akuntansi pajak adalah bidang akuntansi yang berkaitan dengan perhitungan perpajakan, yang mengacu pada peraturan, perundang-undangan, dan aturan pelaksanaan perpajakan.

\section{Pajak}

Mardiasmo (2011:1) mengatakan bahwa pajak adalah iuran rakyat kepada kas negara berdasarkan undang-undang (yang dapat dipaksakan) dengan tiada mendapat jasa timbal (kontraprestasi) yang langsung dapat ditunjukan dan yang digunakan untuk membayar pengeluaran umum. Prasetyono (2011), menyatakan bahwa pajak adalah iuran rakyat kepada kas negara berdasarkan Undang-Undang, sebagai perwujudan pengabdian dan peran serta rakyat untuk membiayai negara dan pembangunan nasional. Y. Sri Pudyatmoko (2009:2) mengatakan bahwa pajak adalah iuran wajib, berupa uang atau barang, yang dipungut oleh penguasa berdasarkan norma-norma hukum, guna menutup biaya produksi barang-barang dan jasa-jasa kolektif dalam mencapai kesejahteraan umum. 


\section{Pajak Penghasilan}

Mardiasmo (2010), menyatakan bahwa sesuai dengan sebutannya pajak penghasilan itu dikenakan atas penghasilan. Pajak penghasilan merupakan salah satu jenis pajak pusat yang obyeknya adalah penghasilan. Pajak penghasilan dikenakan terhadap wajib pajak yaitu apabila telah terpenuhi syarat subyektif dan syarat obyektif sebagamaina ditentukan oleh Undang-Undang Pajak Penghasilan.

\section{Pengertian Pajak Penghasilan Pasal 23}

Purwono (2012), menyatakan bahwa PPh Pasal 23 adalah pemotongan pajak atas penghasilan yang diterima atau Wajip Pajak dalam negeri dan bentuk usaha tetap yang berasal dari modal, penyerahan jasa, atau penyelenggaraan kegiatan selain yang telah dipotong pajak sebagaimana dimaksud dalam pasal 21, yang dibayarkan atau terutang oleh badan pemerintah atau subjek pajak dalam negeri, penyelenggaraan kegiatan, bentuk usaha tetap, atau perwakilan perusahaan luar negeri lainnya.

\section{Dasar Hukum Pajak Penghasilan Pasal 23}

Dasar hukum PPh 23 adalah:

a. Pasal 23 Undang-Undang Nomor 7 Tahun 1983 tentang Pajak Penghasilan sebagaimana telah diubah terakhir dengan Undang-Undang Nomor 36 Tahun 2008 tentang Perubahan Keempat Undang-Undang Nomor 7 Tahun 1983 tentang Pajak Penghasilan.

b. Peraturan Menteri Keuangan Nomor 244/PMK.03/2008 tentang Jenis Jasa Lain sebagaimana dimaksud dalam Pasal 23 ayat (1) Huruf c Angka 2 Undang-Undang Nomor 7 Tahun 1983 tentang Pajak Penghasilan sebagaimana telah beberapa kali diubah terakhir kali dengan Undang-Undang Nomor 36 Tahun 2008.

Cara Menghitung PPh Pasal 23 atas Bunga, termasuk Premium, Diskonto, dan Imbalan karena Jaminan Pengembalian Utang

Atas penghasilan berupa bunga dikenakan pemotongan $\mathrm{PPh}$ Pasal 23 sebesar 15\% dari jumlah bruto.

$$
\text { PPh pasal } 23=15 \% \times \text { Bruto }
$$

Cara Menghitung PPh Pasal 23 atas Imbalan Sehubungan dengan Jasa Teknik, Jasa Manajemen, Jasa Konstruksi, Jasa Konsultan, dan Jasa Lain

Atas penghasilan berupa imbalan sehubungan dengan jasa teknik, jasa manajemen, jasa konstruksi, jasa konsultan, dan jasa lain selain jasa yang telah dipotong Pajak Penghasilan 21 dikenakan pemotongan PPh pasal 23 sebesar $2 \%$ dari jumlah bruto tidak termasuk Pajak Pertambahan Nilai.

$$
\text { PPh pasal } 23=2 \% x \text { Bruto }
$$

\section{Surat Pemberitahuan}

Diana \& Setiawati (2010) Surat pemberitahuan adalah surat yang digunakan oleh Wajib Pajak untuk melaporkan penghitungan dan/atau pembayaran pajak, objek pajak dan/atau bukan objek pajak, dan/atau harta dan kewajiban sesuai dengan ketentuan peraturan perundang-undangan perpajakan. Pajak yang terutang adalah pajak yang harus dibayar pada suatu saat dalam Masa Pajak, dalam Tahun Pajak, tau dalam Bagian Tahun Pajak sesuai dengan ketentuan peraturan perundang-undangan perpajakan. 
Tabel 1. Penelitian Terdahulu

\begin{tabular}{|c|c|c|c|c|c|}
\hline $\begin{array}{l}\text { Nama } \\
\text { Peneliti/Tahun }\end{array}$ & Judul & $\begin{array}{l}\text { Metode } \\
\text { Penelitian }\end{array}$ & Hasil Penelitian & Persamaan & Perbedaan \\
\hline $\begin{array}{l}\text { Najiyullah } \\
\text { (2010) }\end{array}$ & $\begin{array}{l}\text { Analisis } \\
\text { Penghitungan, } \\
\text { Pemotongan, } \\
\text { Penyetoran, dan } \\
\text { Pelaporan } \\
\text { Wajib Pajak } \\
\text { Penghasilan } \\
\text { Pasal 21 Pada } \\
\text { PT. Hikerta } \\
\text { Pratama }\end{array}$ & Kualitatif & $\begin{array}{l}\text { PT. Hikerta Pratama } \\
\text { melaporkan dan menyetorkan } \\
\text { SPT Tahunan Tahun } 2007 \\
\text { PPh 21 telah sesuai dengan } \\
\text { peraturan dan ketentuan yang } \\
\text { berlaku. }\end{array}$ & $\begin{array}{l}\text { Mengacu } \\
\text { pada } \\
\text { penilaian } \\
\text { penghitunga } \\
\text { n, dan } \\
\text { pelaporan } \\
\text { Pajak } \\
\text { Penghasilan. }\end{array}$ & $\begin{array}{l}\text { Terdapat } \\
\text { perbedaan } \\
\text { objek dan } \\
\text { penghitungan } \\
\text { dan pelaporan } \\
\text { Pajak } \\
\text { Penghasilan } \\
23\end{array}$ \\
\hline $\begin{array}{l}\text { Walandouw } \\
\text { (2013) }\end{array}$ & $\begin{array}{l}\text { Analisis } \\
\text { Perhitungan dan } \\
\text { Pelaporan PPh } \\
\text { Pasal 23 dan } \\
\text { PPh Pasal } 25\end{array}$ & Kualitatif & $\begin{array}{l}\text { PPh Pasal } 23 \text { berpengaruh } \\
\text { terhadap besarnya angsuran } \\
\text { PPh Pasal 25 yang harus } \\
\text { dibayarkan perusahaan, } \\
\text { sedangkan PPh Pasal } 25 \text { tidak } \\
\text { mempunyai pengaruh apapun } \\
\text { terhadap PPh Pasal } 23 \text {. }\end{array}$ & $\begin{array}{l}\text { Membahas } \\
\text { perhitungan } \\
\text { dan } \\
\text { pelaporan } \\
\text { PPh Pasal } 23\end{array}$ & $\begin{array}{l}\text { Peneliti tidak } \\
\text { membahas } \\
\text { mengenai PPh } \\
\text { Pasal } 25\end{array}$ \\
\hline
\end{tabular}

Sumber : Data Olahan 2013

\section{Jenis Penelitian}

\section{METODE PENELITIAN}

Dalam melakukan penelitian ini, peneliti mengambil jenis penelitian eksplanasi, dimana penelitian ini dilakukan pada satu variabel mandiri tanpa membuat perbandingan, atau menghubungkan dengan variabel lainnya. Oleh karena itu peneliti bermaksud untuk memberi gambaran secara jelas mengenai masalah yang diteliti yaitu tentang analisis perhitungan dan pelaporan pajak penghasilan pasal 23 pada PT. Hasjrat Multifinance, Manado.

\section{Tempat dan Waktu Penelitian}

Penelitian ini dilakukan di PT Hasjrat Multifinance, Manado yang bertujuan untuk memahami perlakuan penghitungan, dan pelaporan pajak khususnya pada Pajak Penghasilan pasal 23.

\section{Jenis Data}

Menurut Sugiyono (2010:13) dalam penelitian ada dua jenis data yang digunakan yaitu data kuantitatif dan data kualitatif adalah sebagai berikut:

1. Data Kuantitatif dapat diartikan sebagai metode penelitian yang berlandaskan pada filsafat positivism, digunakan untuk meneliti pada populasi atau sampel tertentu, teknik pengambilan sampel pada umumnya dilakukan secara random, pengumpulan data menggunakan instrument penelitian, analisis data bersifat statistik dengan tujuan menguji hipotesis yang telah ditetapkan. Dalam hal ini, data kuantitatif berupa data Surat Setoran Pajak dan Surat Pemberitahuan (SPT) Masa pada PT. Hasjrat Multifinance, Manado.

2. Data Kualitatif dapat diartikan sebagai metode penelitian yang berlandaskan pada filsafat postpositivisme, digunakan untuk meneliti pada kondisi objek yang alamiah, dimana peneliti adalah sebagai instrument kunci, pengambil sampel sumber data dilakukan secara purposive dan snowball, teknik pengumpulan dengan trianggulasi, analisis data bersifat induktif, dan hasil penelitian kualitatif lebih menekankan makna daripada generalisasi. Dalam penelitian ini, data kualitatif adalah data yang disajikan secara deskriptif yaitu berupa sejarah dan struktur organisasi dari PT. Hasjrat Multifinance, Manado.

\section{Sumber Data}

Supardi (2013:16) menyatakan bahwa pengumpulan data dapat menggunakan dua sumber yaitu sumber primer dan sumber sekunder yaitu sebagai berikut:

1. Sumber Primer

Merupakan sumber data yang diperoleh atau dikumpulkan langsung oleh orang yang melakukan penelitian atau yang bersangkutan yang memerlukannya. Data primer disebut juga data asli atau data baru. 


\section{Sumber Sekunder}

Merupakan sumber data yang tidak langsung memberikan data kepada pengumpul data. Data yang diperoleh atau dikumpulkan diperoleh dengan mempelajari bahan-bahan kepustakaan yang berupa peraturan perundang-undangan dan literatur-literatur yang telah ada. Data digunakan dalam penelitian ini berupa data sekunder dari perusahaan yang telah diolah dan diperoleh yang sudah didokumentasikan seperti sejarah dan data Surat Pemberitahuan (SPT) Masa PPh Pasal 23.

\section{HASIL PENELITIAN DAN PEMBAHASAN}

\section{Gambaran Umum PT. Hasjrat Multifinance, Manado}

PT. Hasjrat Multifinance ini adalah perusahaan yang bergerak dibidang pembiayaan. Maksud dari perusahaan pembiayaan adalah suatu bentuk perusahaan yang memfokuskan bisnisnya kepada pemberian dana atau pembiayaan kepada pihak lain atas suatu benda atau barang yang akan diberli atau dimiliki oleh pihak tersebut. Selain itu perusahaan juga melakukan kegiatan pembiayaan dalam bentuk penyediaan barang modal secara finance lease (kegiatan sewa guna usaha dimana penyewaan sewa guna usaha pada akhir masa kontrak mempunyai hak opsi untuk membeli objek sewa guna usaha berdasarkan nilai sisa yang disepakati bersama) maupun secara operating lease (kegiatan sewa guna, dimana penyewa guna usaha tidak mempunyai hak opsi untuk membeli objek sewa guna usaha). PT. Hasjrat Multifinance mempunyai focus bisnis memberikan pembiayaan untuk pembelian kendaraan beroda dua dan empat yaitu untuk merk kendaraan Yamaha dan Toyota.

\section{Tata Cara Pemungutan, Perhitungan PPh 23 PT. Hasjrat Multifinance, Manado}

Pajak Penghasilan pasal 23 merupakan pemotongan pajak atas penghasilan yang diterima atau diperoleh Wajib Pajak Dalam Negeri dan Bentuk Usaha Tetap yang berasal dari modal, penyerahan modal, penyerahan jasa atau penyelenggaraan kegiatan selain yang dipotong PPh Pasal 21. Pemungutan PPh Pasal 23 pada PT. Hasjrat Multifinance, Manado sendiri dikenakan untuk kegiatan jasa lebih khusus untuk Jasa Manajemen, dan Jasa Cleaning Service, serta Biaya Bunga atas denda keterlambatan bayar.

Penyetoran yang dilakukan untuk Jasa Manajemen, dan Jasa Cleaning Service dilakukan setiap bulannya, sedangkan untuk Biaya Bunga (denda keterlambatan bayar) dilakukan setiap tahun kepada perusahaan yang bekerjasama. Dalam hal ini PT. Hasjrat Multifinance dengan PT. Hasjrat Abadi merupakan suatu kesatuan perusahaan yang saling mendukung.

A. Jasa Manajemen

Dalam hal ini, PT. Hasjrat Multifinance yang tidak memiliki kantor cabang di daerah-daerah lain melakukan kerjasama dengan PT. Hasjrat Abadi dalam melakukan pengelolaan administrasi konsumen, dan penerimaan iuran cicilan konsumen sehingga PT Hasjrat Multinance memberikan Fee kepada PT. Hasjrat Abadi atas Jasa Manajemen.

Menghitung PPh Pasal 23 atas Imbalan Sehubungan dengan Jasa Manajemen

PT. Hasjrat Multifinance membayar jasa manajemen sehubungan dengan fee administrasi kepada PT. Hasjrat Abadi yang telah membantu dalam pengurusan data-data konsumen sebesar Rp 79.032.000,00. PPh Pasal 23 yang dipotong oleh PT. Hasjrat Multifinance adalah 2\% x Rp 79.032.000,00 = Rp 1.580.640,00

Perlakuan Akuntansi PPh Pasal 23:

Maka, PT. Hasjrat Multifinance mencatat sebagai berikut:

Biaya Fee Administrasi

Kas

(Mencatat pengeluaran fee)

Kas

Hutang PPh 23

(Mencatat pemungutan PPh Pasal 23)

$$
\begin{array}{r}
\text { Rp 79.032.000,00 } \\
\text { Rp 79.032.000,00 }
\end{array}
$$

$$
\text { Rp 1.580.640,00 }
$$

Rp 1.580.640,00 
Hutang PPh 23

Kas

Rp 1.580.640,00

Rp 1.580.640,00

(Mencatat pembayaran PPh Pasal 23 kepada kas negara)

\section{B. Jasa Cleaning Service}

Dalam hal ini, PT. Hasjrat Multifinance tidak memiliki karyawan khusus untuk tenaga kebersihan sehingga PT. Hasjrat Multifinance bekerjasama dengan CV. Merpati Putih untuk mendapatkan karyawan khusus untuk tenaga kebersihan. Transaksi pembayaran dilakukan antara kedua perusahaan yang kemudian PT. Hasjrat Multifinance yang melakukan pemotongan PPh Pasal 23 kepada CV. Merpati Putih atas Jasa Cleaning Service.

Menghitung PPh Pasal 23 atas Imbalan Sehubungan dengan Jasa Lain (Cleaning Service).

PT. Hasjrat Multifinance membayarkan jasa cleaning service kepada CV. Merpati Putih sebesar Rp 1.767.000,00. PPh Pasal 23 yang dipotong oleh PT. Hasjrat Multifinance adalah sebesar: 2\% x Rp 1.767.000,00 $=\operatorname{Rp} 35.340,00$

Perlakuan Akuntansi PPh Pasal 23:

Maka, PT. Hasjrat Multifinance mencatat sebagai berikut:

Biaya Cleaning Service $\quad$ Rp 1.767.000,00

Kas Rp 1.767.000,00

(Mencatat pengeluaran biaya untuk Cleaning Service)

Kas

Hutang PPh 23

Rp 35.340,00

(Mencatat pemungutan PPh Pasal 23)

Rp 35.340,00

Hutang PPh 23

Kas

Rp 35.340,00

Rp 35.340,00

(Mencatat pembayaran PPh Pasal 23)

C. Biaya Denda atas Keterlambatan Bayar

Dalam pemotongan biaya denda telat bayar, PT. Hasjrat Multifinance dalam kontrak pembiayaan dengan konsumen seringkali terjadi keterlambatan dalam pembayaran iuran sehingga dikenakan denda yang dipotong PPh Pasal 23.

Menghitung PPh Pasal 23 atas Denda Keterlambatan Pembayaran

Konsumen membayar biaya denda atas keterlambatan pembayaran pada PT. Hasjrat Multifinance sebesar Rp 1.000.000,00. Maka PPh Pasal 23 yang dipotong konsumen adalah Rp 1.000.000,00 x 15\% = Rp $150.000,00$.

Perlakuan Akuntansi PPh Pasal 23:

Ketika PT. Hasjrat Multifinance yang membayar sendiri dicatat sebagai berikut:

Biaya Denda Telat Bayar

Kas

Rp 1.000.000,00

Rp 1.000.000,00

(Mencatat pengeluaran denda keterlambatan bayar )

Kas

Rp 150.000,00

Hutang PPh 23

Rp 150.000,00

(Mencatat pemungutan PPh Pasal 23 atas denda keterlambatan bayar) 
Hutang PPh 23

Kas

$\operatorname{Rp} 150.000,00$

(Mencatat pembayaran PPh Pasal 23 ke kas negara)

$$
\text { Rp } 150.000,00
$$

\section{Tata Cara Pelaporan PPh Pasal 23 PT. Hasjrat Multifinance, Manado}

1. PT. Hasjrat Multifinance, Manado harus melaporkan jumlah setoran PPh Pasal 23 yang telah dipungut melalui Surat Setoran Pajak (SSP) kepada Direktorat Jenderal Pajak dalam jangka waktu yang telah ditentukan, paling lambat tanggal 10 bulan berikutnya (apabila jatuh pada hari libur nasional maka penyetoran dilakukan pada hari kerja berikutnya).

2. Surat Pemberitahuan (SPT) Masa Pajak Penghasilan Pasal 23 disertai lampiran dilaporkan selambatlambatnya tanggal 20 bulan berikutnya (apabila jatuh pada hari libur nasional maka pelaporan dilakukan pada hari kerja berikutnya):

a. Daftar Bukti Pemungutan PPh Pasal 23 yang mencantumkan antara lain: Bagian A identifikasi Wajib Pajak (NPWP, Nama, Alamat).

b. Bukti Penyetoran melalui bank dan atau kantor pos yang telah ditentukan oleh pemerintah.

3. Jumlah uang yang tercantum dalam Surat Pemberitahuan (SPT) Masa Pajak Penghasilan Pasal 23 harus sama dengan yang telah disetorkan ke Kas Negara sesuai dengan bukti Surat Setoran Pajak (SSP).

\section{Pembahasan}

Dalam hasil penelitian, PT. Hasjrat Multifinance, Manado sebagai perusahaan pembiayaan konsumen, wajib memungut Pajak Penghasilan (PPh) Pasal 23 sehubungan dengan Biaya Denda keterlambatan bayar, Jasa Manajemen, dan Jasa Lain (Jasa Cleaning Service) yang telah diatur dalam Keputusan Menteri Keuangan Nomor 244/PMK.03/2008 dan telah benar melakukan perhitungan PPh Pasal 23 atas kegiatan-kegiatan tersebut. PT. Hasjrat Multifinance telah melakukan perhitungan PPh Pasal 23 dengan pengenaan Bunga dikenakan 15\% dari pembayaran, dan Jasa Manajemen, Jasa Cleaning Service dikenakan 2\% dari pembayaran. Perhitungan tersebut telah sesuai dengan ketentuan Undang-Undang Nomor 36 Tahun 2008.

Penyetoran dan pelaporan berupa Surat Setoran Pajak (SSP) dan Surat Pemberitahuan (SPT) Masa PT. Hasjrat Multifinance, Manado telah dilakukan sesuai dengan peraturan perpajakan yang berlaku. Penyetoran paling lambat 10 hari dan selanjutnya pelaporan paling lambat 20 hari setelah akhir masa pajak. Dan apabila tanggal penyetoran dan pelaporan tersebut jatuh pada hari libur atau tanggal merah, maka tanggal penyetoran dan pelaporan dapat digeser pada hari kerja berikutnya.

\section{PENUTUP}

\section{Kesimpulan}

Berdasarkan hasil analisis maka dapat disimpulkan bahwa PT. Hasjrat Multifinance, Manado sebagai perusahaan yang bergerak dibidang Leasing khususnya sebagai pembiayaan konsumen sebagaimana yang diatur dalam PMK-244/PMK.03/2008 serta PER-70/PJ/2007, wajib memungut Pajak Penghasilan (PPh) Pasal 23 sehubungan dengan kegiatan perusahaan berupa pengenaan Bunga (denda keterlambatan bayar), dan jasa-jasa dalam hal ini dikenakan jasa manajemen dan jasa cleaning service. Pengenaan besarnya pajak yang dipotong disesuaikan dengan ketentuan Undang-Undang Nomor 36 Tahun 2008, yaitu pengenaan Biaya Denda Atas Keterlambatan Pembayaran dikenakan 15\% dan sehubungan dengan Jasa (Fee, Cleaning Service) dikenakan $2 \%$ dari pembayaran.

PT. Hasjrat Multifinance, Manado dalam penyetoran dan pelaporan pajaknya telah sesuai dengan ketentuan perpajakan yang berlaku, yaitu penyetoran dilakukan dengan menggunakan Surat Setoran Pajak (SSP) paling lambat tanggal 10 bulan berikutnya ke bank/kantor pos. Dan pelaporannya menggunakan Surat Pemberitahuan (SPT) selambat-lambatnya tanggal 20 bulan berikutnya. 


\section{Saran}

Berdasarkan hasil kesimpulan, peneliti dapat memberikan saran yang dapat dijadikan bahan pertimbangan yang berkaitan dengan perhitungan dan pelaporan PPh Pasal 23, perusahaan dapat mempertahankan kinerja karyawan dan terus mencatat secara benar sesuai dengan ketentuan yang telah diatur dalam Undang-Undang Nomor 36 Tahun 2008, berkenaan dengan tarif perhitungan dan pelaporan pajaknya.

\section{DAFTAR PUSTAKA}

Diana, L. Setiawati. 2010. Perpajakan Indonesia Konsep, Aplikasi, \& Penuntun Praktis. ANDI. Yogyakarta.

Muljono, Djoko. 2009. Ketentuan Umum Perpajakan. ANDI. Yogyakarta.

Mardiasmo. 2010. Perpajakan. Edisi Revisi. ANDI. Yogyakarta.

Mardiasmo. 2011. Perpajakan. Edisi Revisi. ANDI. Yogyakarta.

Najiyullah. 2010. Analisis Penghitungan, Pemotongan, Penyetoran, dan Pelaporan Wajib Pajak Penghasilan Pasal 21 Pada PT. Hikerta Pratama.

Republik Indonesia. Permenkeu Nomor 244 tahun 2008 tentang Jenis Jasa Lain PPh 23.

Prasetyono, Sunar. 2011. Panduan Lengkap Tatacara Perhitungan Pajak Penghasilan dan Petunjuk Pengisian SPT. Laksana. Jakarta.

Pudyatmoko, Y, Sri. 2009. Pengantar Hukum Pajak. ANDI. Yogyakarta.

Purwono, Joseph. 2012. Perpajakan Jasa Konstruksi dan Aplikasinya. Gava Media. Yogyakarta.

Sugiyono. 2009. Metode Penelitian Bisnis. Cetakan kesembilan. Edisi Revisi. CV Alberta. Bandung.

Supardi. 2013. Aplikasi Statistika dalam Penelitian. Smart. Jakarta.

Walandouw. 2013. Analisis Perhitungan dan Pelaporan PPh Pasal 23 dan PPh Pasal 25. Skripsi. Universitas Sam Ratulangi. Manado. 